\title{
Indonesia Infant and Young Child Feeding Practice: The Role of Women's Empowerment in Household Domain
}

\author{
Mardiana Dwi Puspitasari ${ }^{1} \&$ Maria Gayatri $^{1}$ \\ ${ }^{1}$ Center for Research and Development of Family Planning and Family Welfare, National Population and Family \\ Planning Board (BKKBN), Jakarta, Indonesia \\ Correspondence: Mardiana Dwi Puspitasari, Center for Research and Development of Family Planning and \\ Family Welfare, National Population and Family Planning Board, Jalan Permata no. 1, Halim Perdana Kusuma, \\ Jakarta, Indonesia. E-mail: mardianadwipuspitasari@gmail.com
}

Received: June 13, 2020 Accepted: July 6, 2020 Online Published: July 13, 2020

doi:10.5539/gjhs.v12n9p129

URL: https://doi.org/10.5539/gjhs.v12n9p129

\begin{abstract}
Previous studies showed the significant association between women's empowerment and infant and young child feeding (IYCF) practice. Only around $40 \%$ of Indonesian children met adequate IYCF practice. Hence, each dimension of women's empowerment in the household domain must be explored.

We carried out a dataset of the 2017 Indonesia Demographic and Health Survey, with samples of 4,880 mothers of reproductive age in a marriage relationship with their last-born child aged 6-23 months. Logistic regression was applied.

Mother with legal asset ownerships had lower odds of her child meeting (aOR: 0.83; 95\% CI: 0.72, 0.95) minimum dietary diversity (MDD), (aOR: 0.75; 95\% CI: 0.65, 0.87) minimum meal frequency (MMF) and (aOR: $0.74 ; 95 \%$ CI: $0.61,0.90)$ minimum acceptable diet (MAD). Mother who could control her own earnings had higher odds of her child meeting MDD (aOR: 1.52; 95\% CI: 1.32, 1.74) and MAD (aOR: 1.62; 95\% CI: 1.34, 1.94). Employed mother had higher odds of meeting MMF (aOR: 1.58; 95\% CI: 1.38, 1.82). Mother who did not approve of intimate partner violence was more likely to feed her child with MDD (1.39 times), MMF (1.41 times) and MAD (2.04 times). Mother with three or more parity had lower odds of her child meeting MDD (aOR: 0.81; 95\% CI: 0.79, 0.93), MMF (aOR: 0.84; 95\% CI: 0.72, 0.99) and MDD (aOR: 0.80; 95\% CI: 0.65, 1.00).

Mother who did not approve towards domestic violence, was working, controlled her assets and had a maximum of two parity was associated with official IYCF recommendation.
\end{abstract}

Keywords: women's empowerment, infant and young child feeding practice, Indonesia

\section{Introduction}

Child nutritional status is very important for a child's growth and development. The growth and development of children are sensitive to what and how they are fed from birth to two years. Optimal breastfeeding and adequate complementary feeding practice for infants and young children before two years old were the protective factors against stunting and wasting (Weise, 2014; WHO, 2006). Hence, Infant and Young Child Feeding (IYCF) practice provided to infant and young child 6-23 months of age was very important for child's growth and development (Ahmad, Madanijah, Dwiriani, \& Kolopaking, 2018; Dhami, Ogbo, Osuagwu, Ugboma, \& Agho, 2019b; Harding, Aguayo, \& Webb, 2018).

Naturally, a mother was a child's first link of emotional bonding and attachment. Child's emotional relationship with his mother was closer than his relationship with his father (Si Han \& Pei Jun, 2013). This emotional attachment was very important for mother's subjective well-being (Fernandez, Della Giusta, \& Kambhampati, 2015) and early childhood development (Weise, 2014; WHO, 2006). Prior studies indicated that women's empowerment was associated with IYCF practice (Dhami, Ogbo, Osuagwu, \& Agho, 2019a; Ickes, Wu, Mandel, \& Roberts, 2018; J. R. Khan, Awan, \& Sheikh, 2019; Na, Jennings, Talegawkar, \& Ahmed, 2015; Tassew, Tekle, Belachew, \& Adhena, 2019).

Indonesia has made significant progress in the area of women's empowerment for years. Gender Empowerment Index (IPG) was at 72.10 in 2018 , indicating that Indonesian women had a significant power in national politics and economic development (Statistics Indonesia (BPS), n.d). It was supported by female labour participation rate 
(FLPR) at 55.50 in February 2019, as identified in 2019 Indonesia Labour Force Survey (Statistics Indonesia (BPS), 2019). On the other hand, the 2017 Indonesia Demographic and Health Survey showed only around $40 \%$ of young children aged 6-23 months met adequate IYCF practice.

Child feeding is a form of parenting practices. Marital relationship, a form of contextual sources of stress and support, contributed to parenting behaviour (Belsky, 1984). The more harmony of marital relationship, the higher likelihood of better parenting practices and adequate feeding practice provision. Yet, the impact of women's empowerment in domestic life was still contradictory. Some studies reported that asset ownerships and control over own assets made women to be empowered in the household (Mishra \& Sam, 2016; Murshid, 2018), but to some extent, giving a mother access to asset ownerships, education, employment and community participation was unlikely to be automatically empowering in herself in patriarchy household (Bulte \& Lensink, 2019; Cornish et al., 2019; Samarakoon \& Parinduri, 2015).

Regarding the high level of Indonesia IPG, the implementation of women's empowerment needs to be directed to contribute in the household context, especially to improve IYCF practice. According to Gram, Morrison, \& Skordis-Worrall (2019), women's empowerment was a complex construct, ranging from self-efficacy reliance until third-party support. Hence, we need to explore each dimension of women's empowerment as each single construct, in order to prevent the predictive value of women's empowerment on IYCF practice from being reduced. We applied dimensions provided in Indonesian Demographic and Health Survey, covering economic, socio-familial and legal empowerment (Na et al., 2015).

\subsection{Aim of the Study}

This study aimed to evaluate the effect of women's empowerment on IYCF practice in Indonesia, exercised by each indicator of empowerment. We consider that examining each dimension of women's empowerment to be a useful tool in describing and analysing how women's empowerment has a function in a specific context and how IYCF practice improves with regard to mothering practice.

\section{Method}

\subsection{Data}

This study used the 2017 Indonesia Demographic and Health Survey (IDHS), a nation-wide survey conducted in 34 provinces of Indonesia. The survey used the Master Sample of census blocks of the 2010 Indonesia national census as the sample frame. Households-list in the selected census blocks was updated prior to the survey. Two-stage stratified sampling was conducted. First, systematic sampling proportional to size to select a number of census blocks, whereas the census blocks were varied by urban and rural areas, and ordered by wealth index category. Second, random selection of 25 ordinary households in each selected block with systematic sampling. There were 1,970 census blocks in urban and rural areas, with expected 49,250 households and 59,100 women aged 15-49 years responses.

In this study, we used the women's questionnaire which collected data on women of reproductive aged 15-49 years and information on women's empowerment and child health and nutrition. The samples were restricted to the last birth during two years preceding the survey. Those last birth were aged 6-23 months and living with their mother. The final sample size was 4,880 women of reproductive age (15-49 years old) in a marriage or partnership relationship.

The inclusion criteria were: (1) the youngest children aged 6-23 months; (2) the children were living with their mother who were fed, disaggregated by whether breastfeeding or not. The exclusion criteria were: (1) Children aged 6-23 months who had suffered from acute illness; (2) Children whose mothers had died; (3) Multiple birth children such as twins, triplets, quadruplets, etc; and (4) Children whose mothers answered "don't know" on the questions of solid, semi-solid or soft foods. 


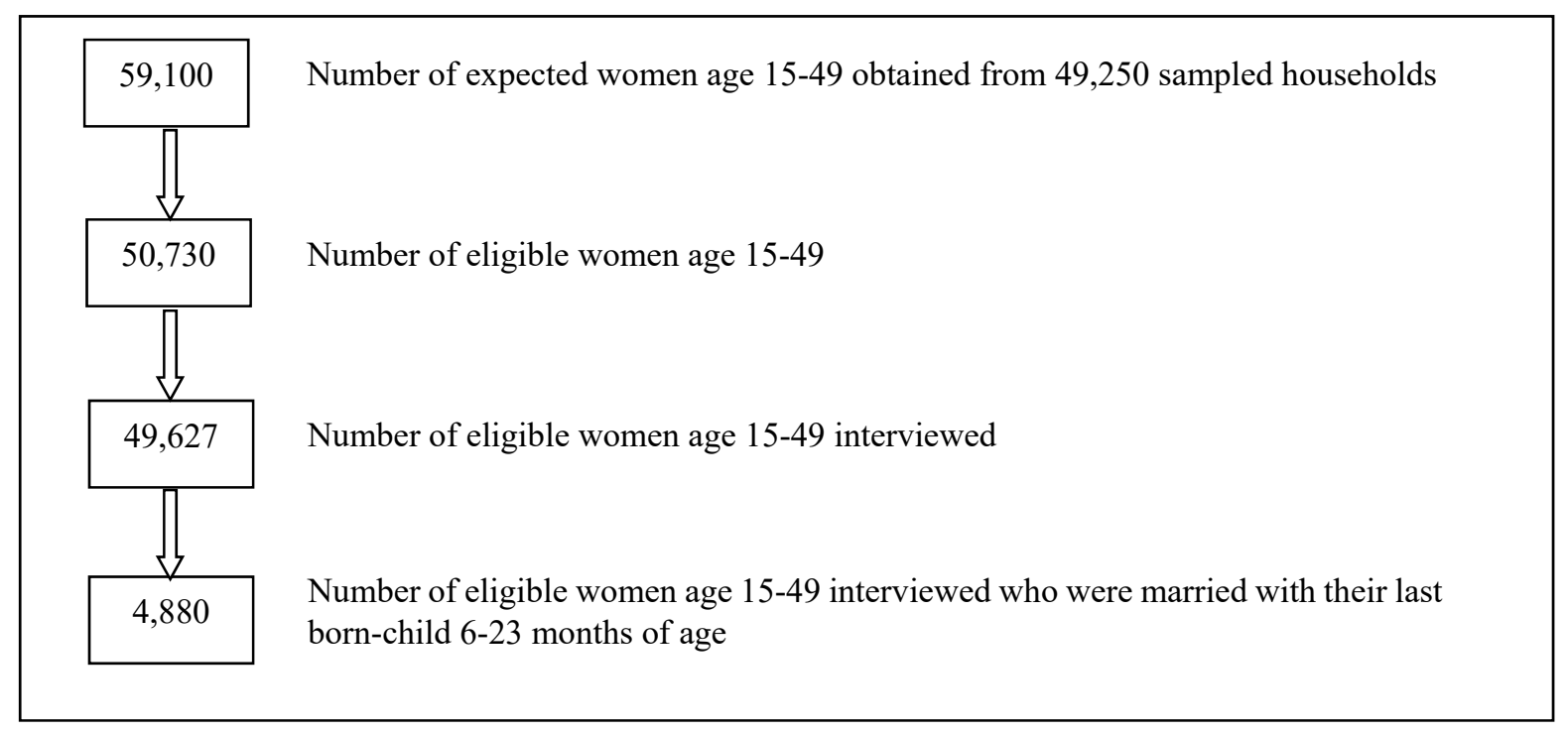

Figure 1. The flow chart of sample selection

\subsection{Study Variables \\ Infant and Young Child Feeding (IYCF) Practice}

There were two groups of participants in this study. The first group was mothers who fed their last-born child age 6-23 months with official IYCF practice recommendation, and the second group was otherwise. The children of the first group met minimum dietary diversity (MDD), minimum meal frequency (MMF) and minimum acceptable diet (MAD), as the indicators of IYCF practice proposed by WHO. Guide to DHS 7 was used as a reference to define each indicator (IFC, 2018). Minimum dietary diversity was defined as infant and young child age 6-23 months who received foods from at least four out of seven food groups in the previous day (grains, roots, tubers; legumes and nuts; dairy products; flesh foods; eggs; vitamin A rich fruits and vegetables; and other fruits and vegetables). Minimum meal frequency was defined as infant and young child 6-23 months of age who received solid, semi-solid or soft foods with minimum number, which was varied by child age and breast-feeding status, during the past day. The minimum meal frequency was defined as 1) two times for breastfed infant 6-8 months, 2) three times for breastfed infant and young child 9-23 months, and 3) four times for non-breastfed infant and young child 6-23 months. The last indicator, minimum acceptable diet, was based on minimum dietary diversity and minimum meal frequency fed to the infant and young child 6-23 months the day prior to the interview. Each indicator was a binary variable. A value of ' 1 ' was assigned if the respondent engaged in each indicator, otherwise a value of ' 0 ' was assigned.

\section{Women Empowerment Indicators}

Kabeer (1999) defines women's empowerment as “... the process by which those who have been denied the ability to make strategic life choices acquire such an ability". In our analysis, we evaluate whether a mother in a marriage relationship could exercise her resources for achievement in relation to her last-born child 's wellbeing.

Based on $\mathrm{Na}$ et al. (2015), women's empowerment in DHS measures had three dimensions: economic empowerment, legal empowerment and socio-familial empowerment. Each indicator constructed the dimensions was exercised separately.

The first two indicators were economic empowerment: mother employment and mother's control over her cash earning. Mother employment was defined as mother employed in 12 months prior to the survey with earning in the forms of cash only, cash and in-kind, and in-kind only. Control over women's cash earning was based on the mother who decided how her cash earning was used or distributed by whether the mother earned less or more than her husband. Each indicator was a binary variable with a value of ' 1 ' and ' 0 '.

Ownership of assets was a single form of legal empowerment. This indicator was defined as the mother's or father's legal ownership of both house and land. We scored ' 1 ' if the mother engaged in this indicator, otherwise was ' 0 '. 
Socio-familial empowerment was constructed by involvement in decision-making and attitude towards wife beating indicators. Involvement in decision-making was defined as the number of decisions in which a mother made a specific decision alone or jointly with her husband/partner for her own health care, large household purchases and visits to family/relatives. The number of decisions in which women participate is categorized into "0", "1-2", and "3". Attitude towards wife beating indicators was defined as the number of reasons for which wife-beating was justified. The reasons were burning food, arguing with the husband/partner, going out without telling the husband, neglecting the children and refusing to have sexual intercourse with the husband/partner. The number of reasons for which wife beating is justified was categorized into "0", "1-2", "3-4", and "5".

\section{Socio-Demographic Characteristics}

Socio-demographic predictors in our study included individual-mother, individual-child, family and environment characteristics. Mother's age and number of children were individual-mother characteristics. Mother's age was coded as mothers age 15-24, 25-34 and 35-49 years old. Number of children was classified as mothers with 1-2 children and 3 or more children. The ideal number of two-children in the family is a family planning policy in Indonesia. Children's age and sex represented individual-child characteristics. Child's age was categorised as 6-8, 9-11, 12-17 and 18-23 months of age. Child's sex consisted of male and female. Household's wealth index described family characteristics and was classified as poor, middle and rich households. Household's wealth index was calculated based on household's ownership of a number of assets such as television and car; dwelling characteristics such as flooring material; source of drinking water; toilet facilities and other indicators related to wealth status. The Demographic and Health Survey had standardized each household score for each asset then generated the factor score using principal components analysis to define wealth quintiles into five groups (lowest, second, middle, fourth and highest). Finally, the region was an environment characteristic and categorized as urban and rural areas.

\subsection{Statistical Analysis}

Data analysis was computed using STATA 15.1. In the beginning, we used descriptive analysis to show the distribution of the samples based on the variables. Then, logistic regression was carried out to view the association for each of IYCF practice with all predictors. First, bivariate logistic regression was performed between dependent and each independent variables. Second, multivariate logistic regression was performed between dependent and all independent variables simultaneously. Only significant independent variables in the bivariate logistic regression were included in the multivariate logistic regression (if the $\mathrm{p}$-value $<\alpha=0.05$ ).

\subsection{Ethical Consideration}

The study used the existing dataset of 2017 Indonesia Demographic and Health Survey, downloaded by registering from the DHS website. Personal identity, such as name and address, was not included when downloading the dataset. Therefore, no separate ethical approval is required for using the data.

\section{Results}

\subsection{Demographic Characteristics and Empowerment Characteristics}

A total of 4,880 mothers of reproductive age with their last-born child aged 6-23 months met the criterion for this analysis. There were 2,$929 ; 1,093$; and 577 of children meeting minimum dietary diversity, minimum meal frequency and minimum acceptable diet, respectively.

Table 1 provides distribution among mothers with their child 6-23 months of age in Indonesia. In the descriptive analysis, the majority of mothers were aged 25-34 years old (52.07\%), whereas $25 \%$ and $22.92 \%$ were aged $35-49$ years and $15-24$ years, respectively. About $67.89 \%$ of mothers had one to two children, while only around $32.11 \%$ of mothers had three or more children. There were similar percentages for child's sex in this study, accounting for $51.95 \%$ and $48.05 \%$ for males and females, respectively. 
Table 1. Socio-demographic characteristics of mothers with their child 6-23 months of age, Indonesia $(\mathrm{N}=4,880)$

\begin{tabular}{|c|c|c|}
\hline Characteristics & n (weighed) & $\%$ \\
\hline \multicolumn{3}{|l|}{ Individuals-level factors } \\
\hline \multicolumn{3}{|l|}{ Mother's age (years) } \\
\hline $15-24$ & 1,119 & 22.92 \\
\hline $25-34$ & 2,541 & 52.07 \\
\hline $35-49$ & 1,220 & 25.00 \\
\hline \multicolumn{3}{|l|}{ Mother's number of children } \\
\hline $1-2$ & 3,313 & 67.89 \\
\hline 3 or more & 1,567 & 32.11 \\
\hline \multicolumn{3}{|c|}{ Control over Women's Cash Earnings } \\
\hline No & 3,172 & 65.01 \\
\hline Yes & 1,707 & 34.99 \\
\hline \multicolumn{3}{|l|}{ Ownership of Assets } \\
\hline No & 2,462 & 50.45 \\
\hline Yes & 2,418 & 49.55 \\
\hline \multicolumn{3}{|l|}{ Mother's working status } \\
\hline Not working & 2,714 & 55.61 \\
\hline Working & 2,166 & 44.39 \\
\hline \multicolumn{3}{|c|}{ Number of decisions in which women participate } \\
\hline 0 & 294 & 6.03 \\
\hline $1-2$ & 1,386 & 28.40 \\
\hline 3 & 3,200 & 65.57 \\
\hline \multicolumn{3}{|c|}{ Number of reasons for which wife beating is justified } \\
\hline 0 & 3,357 & 68.79 \\
\hline $1-2$ & 1,210 & 24.80 \\
\hline $3-4$ & 282 & 5.77 \\
\hline 5 & 31 & 0.64 \\
\hline \multicolumn{3}{|l|}{ Sex of child } \\
\hline Male & 2,535 & 51.95 \\
\hline Female & 2,345 & 48.05 \\
\hline \multicolumn{3}{|l|}{ Age of child (months) } \\
\hline 6-8 & 773 & 15.83 \\
\hline $9-11$ & 851 & 17.44 \\
\hline $12-17$ & 1,726 & 35.36 \\
\hline $18-23$ & 1,530 & 31.36 \\
\hline \multicolumn{3}{|l|}{ Household level } \\
\hline \multicolumn{3}{|l|}{ Household Wealth Index } \\
\hline Poor & 1,924 & 39.42 \\
\hline Middle & 952 & 19.52 \\
\hline Rich & 2,004 & 41.06 \\
\hline \multicolumn{3}{|l|}{ Place of residence } \\
\hline Urban & 2,398 & 49.13 \\
\hline Rural & 2,482 & 50.87 \\
\hline TOTAL & 4,880 & 100.00 \\
\hline
\end{tabular}


Stratified by each dimension of women's empowerment, there were $55.61 \%$ of mothers who were working and around $44.39 \%$ of mothers were not at the employment nor earned the income. About $65.01 \%$ of mothers had the power to control their own cash earnings, but only approximately $34.99 \%$ were otherwise. There was an almost equal distribution for ownership of assets, with about half of mothers having legal assets (home and land). The majority of mothers $(65.57 \%)$ could participate in decision-making with regard to their own health care, large household purchases and visits to family or relatives, whereas about $28.4 \%$ could participate in two of three decision-making processes and only around $6.03 \%$ could not participate in any decision-making process. There were $68.79 \%$ of mothers did not have attitudinal acceptance towards intimate partner violence in any circumstances, yet around $24.8 \%$ and $5.77 \%$ mothers had positive attitudes towards one to two and three to four indicators of wife beating, respectively. Ironically, there were mothers in relatively small proportion amongst others $(0.64 \%)$ who had a positive attitude towards domestic violence in any circumstances.

There was an almost equal distribution for mothers who lived in urban and rural areas, by $49 \%$ and $51 \%$, respectively. Finally, the majority of mothers lived in rich households $(41.06 \%)$, whereas about $39.42 \%$ were poor and only around $19.52 \%$ lived in moderate household status.

In bivariate analysis, there were no significant differences in infants and young children who met minimum dietary diversity (table 2), minimum meal frequency (table 3) and minimum acceptable diet (table 4) requirements in maternal age and participation in the decision-making process.

\subsection{Minimum Dietary Diversity}

Bivariate analysis shows that infants and young children who met minimum dietary diversity were the ones who were female, older, whose mother with a maximum two parity, whose mother was working, whose mother did not have legal assets, but whose mothers had the power to control her own earnings, whose mothers did not have attitudinal acceptance of intimate partner violence in any circumstances, lived in urban areas and with higher economic status (table 2).

Table 2. Logistic Regression for the predictors of mother to feed her child 6-23 months of age meeting minimum dietary diversity, Indonesia ( $\mathrm{N}=4$ 880)

\begin{tabular}{|c|c|c|c|c|}
\hline \multirow{2}{*}{ Outcome Variable } & \multicolumn{2}{|c|}{ Unadjusted } & \multicolumn{2}{|c|}{ Adjusted } \\
\hline & OR & 95\% CI & OR & 95\% CI \\
\hline \multicolumn{5}{|c|}{ Meeting minimum dietary diversity } \\
\hline \multicolumn{5}{|c|}{ Mother's age (years) } \\
\hline \multicolumn{5}{|l|}{$15-24$} \\
\hline $25-34$ & 0.95 & $0.82 ; 1.10$ & & \\
\hline $35-49$ & 0.92 & $0.78 ; 1.08$ & & \\
\hline \multicolumn{5}{|c|}{ Mother's number of children } \\
\hline \multicolumn{5}{|c|}{$1-2$} \\
\hline 3 or more & $0.81 * *$ & $0.72 ; 0.91$ & $0.81 * *$ & $0.79 ; 0.93$ \\
\hline \multicolumn{5}{|c|}{ Control over Women's Cash Earnings } \\
\hline \multicolumn{5}{|c|}{ No } \\
\hline Yes & $1.65^{* *}$ & $1.46 ; 1.87$ & $1.52 * *$ & $1.32 ; 1.74$ \\
\hline \multicolumn{5}{|c|}{ Ownership of Assets } \\
\hline \multicolumn{5}{|c|}{ No } \\
\hline Yes & $0.88^{*}$ & $0.036 ; 0.79$ & $0.83 * *$ & $0.72 ; 0.95$ \\
\hline \multicolumn{5}{|c|}{ Mother's working status } \\
\hline \multicolumn{5}{|c|}{ Not working } \\
\hline Working & $1.36^{* *}$ & $0.21 ; 1.53$ & & \\
\hline
\end{tabular}




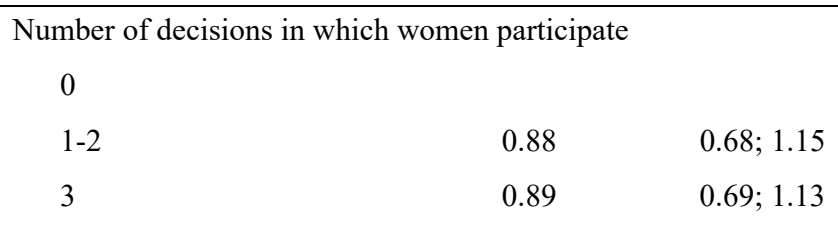

$\begin{array}{lllll}\text { Number of reasons for which wife beating is justified } & & \\ 0 & & & & \\ 1-2 & 0.95 & 0.83 ; 1.08 & 0.99 & 0.85 ; 1.15 \\ 3-4 & 0.67^{* *} & 0.52 ; 0.85 & 0.72^{*} & 0.55 ; 0.94 \\ 5 & 0.58 & 0.28 ; 1.17 & 0.79 & 0.37 ; 1.68\end{array}$

\begin{tabular}{|c|c|c|c|c|}
\hline \multicolumn{5}{|l|}{ Sex of child } \\
\hline \multicolumn{5}{|l|}{ Male } \\
\hline Female & $1.13^{*}$ & $1.01 ; 1.27$ & & \\
\hline \multicolumn{5}{|c|}{ Age of child (months) } \\
\hline \multicolumn{5}{|l|}{$6-8$} \\
\hline $9-11$ & $3.77 * *$ & $3.04 ; 4.67$ & $4.25^{* *}$ & $3.40 ; 5.32$ \\
\hline $12-17$ & $7.22 * *$ & $5.93 ; 8.79$ & $8.86^{* *}$ & $7.21 ; 10.89$ \\
\hline $18-23$ & $9.86^{* *}$ & $8.04 ; 12.09$ & $11.91 * *$ & $9.62 ; 14.74$ \\
\hline \multicolumn{5}{|c|}{ Household Wealth Index } \\
\hline \multicolumn{5}{|l|}{ Poor } \\
\hline Middle & $1.66^{* *}$ & $1.42 ; 1.95$ & $1.66^{* *}$ & $1.39 ; 1.98$ \\
\hline Rich & $2.47^{* *}$ & $2.17 ; 2.81$ & $2.46^{* *}$ & $2.10 ; 2.90$ \\
\hline \multicolumn{5}{|c|}{ Place of residence } \\
\hline \multicolumn{5}{|l|}{ Rural } \\
\hline Urban & $1.6^{* *}$ & $1.42 ; 1.79$ & $1.16^{*}$ & $1.01 ; 1.34$ \\
\hline
\end{tabular}

Note. $*(\mathrm{p}<0.05) ; * *(\mathrm{p}<0.01)$.

In the final model with adjusted for other factors (table 2), children aged 18-23 months had the highest odds of meeting minimum dietary diversity (aOR: 11.91; 95\% CI, $9.62-14.74$ ). Based on economic status, the wealthiest children (aOR: 2.46 ; 95\% CI: 2.10, 2.90) had the highest odds of meeting minimum dietary diversity. Children living in urban areas were 1.16 times more able to meet the minimum dietary diversity than those who live in rural areas. With regard to women's empowerment context, mothers who had one to two children would be 1.23 times able to reduce the likelihood of a child not being fed a minimum dietary diversity requirement compared to those who had three or more children. Mothers who could control their own earnings had higher odds of their children meeting minimum dietary diversity compared to those who could not (aOR: $1.52 ; 95 \%$ CI: $1.32,1.74$ ). Mothers who did not accept domestic violence in any circumstances were 1.39 times more likely to prevent their children from not being fed with minimum dietary diversity requirements than those who agreed with three to four forms of wife beating. On the other hand, mothers who did not have legal ownership of assets were 1.20 times more likely to prevent children of not being fed with minimum dietary diversity compared to those who have legal assets.

\subsection{Minimum Meal Frequency}

Table 3 gave information that infants and young children who met minimum meal frequency were those who were male, advanced age, whose mother had one to two children, whose mother was at the employment, whose mother did not have legal assets, but whose mother controlled her own earnings, whose mother did not agree on wife beating in any forms, lived in urban areas and with higher economic status. 
Table 3. Logistic Regression for the predictors of mother to feed her child 6-23 months of age meeting minimum meal frequency, Indonesia $(\mathrm{N}=4880)$

\begin{tabular}{|c|c|c|c|c|}
\hline \multirow{2}{*}{ Outcome Variable } & \multicolumn{2}{|c|}{ Unadjusted } & \multicolumn{2}{|c|}{ Adjusted } \\
\hline & OR & $95 \%$ CI & OR & $95 \% \mathrm{CI}$ \\
\hline \multicolumn{5}{|c|}{ Meeting minimum meal frequency } \\
\hline \multicolumn{5}{|c|}{ Mother's age (years) } \\
\hline \multicolumn{5}{|l|}{$15-24$} \\
\hline $25-34$ & 0.94 & $0.80 ; 1.11$ & & \\
\hline $35-49$ & 0.89 & $0.73 ; 1.08$ & & \\
\hline \multicolumn{5}{|c|}{ Mother's number of children } \\
\hline \multicolumn{5}{|c|}{$1-2$} \\
\hline 3 or more & $0.78^{* *}$ & $0.7 ; 0.90$ & $0.84^{*}$ & $0.72 ; 0.99$ \\
\hline \multicolumn{5}{|c|}{ Control over Women's Cash Earnings } \\
\hline \multicolumn{5}{|l|}{ No } \\
\hline Yes & $1.76^{* *}$ & $1.53 ; 2.02$ & & \\
\hline \multicolumn{5}{|c|}{ Ownership of Assets } \\
\hline \multicolumn{5}{|c|}{ No } \\
\hline Yes & $0.75^{* *}$ & $0.65 ; 0.86$ & $0.75^{* *}$ & $0.65 ; 0.87$ \\
\hline \multicolumn{5}{|c|}{ Mother's working status } \\
\hline \multicolumn{5}{|l|}{ Not working } \\
\hline Working & $1.71 * *$ & $1.49 ; 1.96$ & $1.58 * *$ & $1.38 ; 1.82$ \\
\hline
\end{tabular}

Number of decisions in which women participate

0

$1-2$

0.92

$0.68 ; 1.24$

3

1.04

$0.78 ; 1.38$

Number of reasons for which wife beating is justified

$$
0
$$

$3-4$

0.87

$0.61 * *$

$0.74 ; 1.02$

0.91

$0.77 ; 1.08$

5

0.69

$0.44 ; 0.85$

0.71 *

$0.41 ; 0.96$

$0.27 ; 1.75$

1.04

$0.40 ; 2.69$

\begin{tabular}{|c|c|c|c|c|}
\hline \multicolumn{5}{|l|}{ Sex of child } \\
\hline \multicolumn{5}{|l|}{ Male } \\
\hline Female & $0.81 * *$ & $0.71 ; 0.93$ & $0.78 * *$ & $0.68 ; 0.90$ \\
\hline \multicolumn{5}{|c|}{ Age of child (months) } \\
\hline \multicolumn{5}{|l|}{$6-8$} \\
\hline $9-11$ & $1.57 * *$ & $1.20 ; 2.06$ & $1.66^{* *}$ & $1.26 ; 2.19$ \\
\hline $12-17$ & $1.66^{* *}$ & $1.31 ; 2.10$ & $1.85 * *$ & $1.45 ; 2.35$ \\
\hline $18-23$ & $2.94 * *$ & $2.33 ; 3.72$ & $3.20 * *$ & $2.52 ; 4.06$ \\
\hline \multicolumn{5}{|c|}{ Household Wealth Index } \\
\hline \multicolumn{5}{|l|}{ Poor } \\
\hline Middle & $1.56^{* *}$ & $1.28 ; 1.91$ & $1.41^{* *}$ & $1.14 ; 1.73$ \\
\hline Rich & $2.38 * *$ & $2.03 ; 2.78$ & $1.98 * *$ & $1.65 ; 2.73$ \\
\hline
\end{tabular}


Place of residence

Rural
Urban
$1.75^{* *}$

Note: ${ }^{*}(\mathrm{p}<0.05)$; $* *(\mathrm{p}<0.01)$.

Final model of multivariate analysis (table 3) shows that male children had 1.28 times more likely to be fed with minimum meal frequency relative to female children. The adjusted odds ratio was the highest amongst children age 18-23 months by 3.20 times relative to the youngest children age 6-8 months. The wealthiest children were 1.98 times more likely to meet minimum meal frequency. Children who lived in urban areas had higher odds of meeting minimum meal frequency compared to those who lived in rural areas (aOR: 1.31; 95\% CI: 1.12, 1.53). Regarding women's empowerment indicators, mothers who had one or two children were 1.19 times more likely to prevent their children from not being fed with minimum meal frequency requirements than those who had three to more children. Mothers who were working had higher odds of meeting minimum meal frequency than those who were not. Mothers who did not approve towards wife beating in any form had 1.41 times more likely to prevent their children from not being fed with minimum meal frequency compared to those who approved towards three to four forms of wife beating. However, mothers who did not have legal assets as much as 1.33 times could prevent their children from not being fed with minimum meal frequency compared to those who have legal assets ownership.

\subsection{Minimum Acceptable Diet}

In bivariate analysis (table 4), the predictors of infants and young children met the minimum acceptable diet was the same as those for the child being fed with minimum meal frequency. Those who met the minimum acceptable diet were the children who were male, advanced age, whose mother with a maximum of two parity, whose mother had earnings and controlled her own earnings, whose mother did not have legal assets, whose mother had a negative attitude towards wife beating, lived in urban areas and with higher economic status.

Table 4. Logistic Regression for the predictors of mother to feed her child 6-23 months of age meeting minimum acceptable diet in Indonesia $(\mathrm{N}=4880)$

\begin{tabular}{|c|c|c|c|c|}
\hline \multirow{2}{*}{ Outcome Variable } & \multicolumn{2}{|c|}{ Unadjusted } & \multicolumn{2}{|c|}{ Adjusted } \\
\hline & OR & $95 \%$ CI & OR & $95 \%$ CI \\
\hline \multicolumn{5}{|c|}{ Meeting minimum Acceptable Diet } \\
\hline \multicolumn{5}{|c|}{ Mother's age (years) } \\
\hline \multicolumn{5}{|l|}{$15-24$} \\
\hline $25-34$ & 0.95 & $0.77 ; 1.18$ & & \\
\hline $35-49$ & 0.87 & $0.68 ; 1.12$ & & \\
\hline \multicolumn{5}{|c|}{ Mother's number of children } \\
\hline \multicolumn{5}{|l|}{$1-2$} \\
\hline 3 or more & $0.72 * *$ & $0.59 ; 0.88$ & $0.80^{*}$ & $0.65 ; 1.00$ \\
\hline \multicolumn{5}{|c|}{ Control over Women's Cash Earnings } \\
\hline \multicolumn{5}{|l|}{ No } \\
\hline Yes & $1.89^{* *}$ & $1.59 ; 2.25$ & $1.62 * *$ & $1.34 ; 1.94$ \\
\hline \multicolumn{5}{|c|}{ Ownership of Assets } \\
\hline \multicolumn{5}{|l|}{ No } \\
\hline Yes & $0.74 * *$ & $0.62 ; 0.89$ & $0.74 * *$ & $0.61 ; 0.90$ \\
\hline \multicolumn{5}{|c|}{ Mother's working status } \\
\hline \multicolumn{5}{|l|}{ Not working } \\
\hline Working & $1.66^{* *}$ & $0.14 ; 1.98$ & & \\
\hline
\end{tabular}




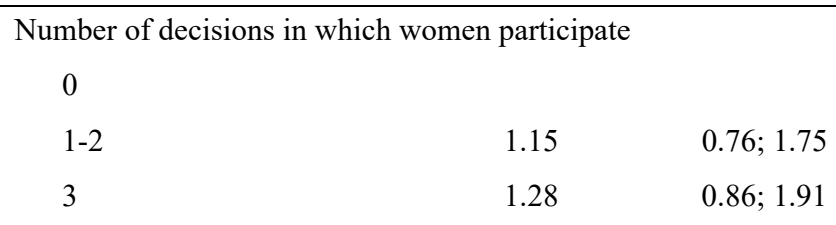

\begin{tabular}{|c|c|c|c|c|}
\hline \multicolumn{5}{|c|}{ Number of reasons for which wife beating is justified } \\
\hline \multicolumn{5}{|l|}{0} \\
\hline $1-2$ & 0.82 & $0.66 ; 1.01$ & 0.87 & $0.70 ; 1.08$ \\
\hline $3-4$ & $0.40^{* *}$ & $0.24 ; 0.67$ & $0.49^{*}$ & $0.29 ; 0.84$ \\
\hline 5 & 0.81 & $0.26 ; 2.54$ & 1.50 & $0.46 ; 4.92$ \\
\hline \multicolumn{5}{|l|}{ Sex of child } \\
\hline \multicolumn{5}{|l|}{ Male } \\
\hline Female & $0.80^{*}$ & $0.67 ; 0.95$ & $0.74 * *$ & $0.62 ; 0.89$ \\
\hline \multicolumn{5}{|c|}{ Age of child (months) } \\
\hline \multicolumn{5}{|l|}{ 6-8 } \\
\hline $9-11$ & $3.43 * *$ & $2.07 ; 5.69$ & $3.68^{* *}$ & $2.21 ; 6.14$ \\
\hline $12-17$ & $5.27 * *$ & $3.31 ; 8.40$ & $6.18^{* *}$ & $3.86 ; 9.89$ \\
\hline $18-23$ & $8.13^{* *}$ & $5.12 ; 12.90$ & $9.19^{* *}$ & $5.76 ; 14.66$ \\
\hline \multicolumn{5}{|c|}{ Household Wealth Index } \\
\hline \multicolumn{5}{|l|}{ Poor } \\
\hline Middle & $2.28^{* *}$ & $1.74 ; 2.99$ & $1.99^{* *}$ & $1.50 ; 2.65$ \\
\hline Rich & $3.41^{* *}$ & $2.73 ; 4.26$ & $2.75^{* *}$ & $2.14 ; 3.54$ \\
\hline \multicolumn{5}{|c|}{ Place of residence } \\
\hline \multicolumn{5}{|l|}{ Rural } \\
\hline Urban & $2.00^{* *}$ & $1.67 ; 2.39$ & $1.31^{* *}$ & $1.07 ; 1.60$ \\
\hline
\end{tabular}

Note. $*(\mathrm{p}<0.05) ; * *(\mathrm{p}<0.01)$.

The final model in table 4 shows that child's age had the strongest influence on meeting minimum acceptable diet, with children age 18-23 months were 9.19 more likely to meet minimum acceptable diet relative to the youngest children (6-8 months). Male children were 1.35 times more likely to be fed with a minimum acceptable diet relative to female children. The wealthiest children had the highest odds of meeting minimum meal frequency among other economic status (aOR: 2.75; 95\% CI: 2.14, 3.54). Children who lived in urban areas had 1.31 more likely to meet minimum meal frequency compared to those who lived in rural areas. Based on women's empowerment indicators, nulliparous mothers, especially those who had one to two children were 1.25 times more likely to prevent their children from not being fed with a minimum acceptable diet relative to mothers with three or more children. Mothers who could control their own earnings had higher odds of meeting a minimum acceptable diet relative to those who could not. Mothers who did not agree on any circumstance of intimate partner violence were 2.04 times more likely to prevent their children from not being fed with a minimum acceptable diet compared to those who agreed on three to four forms of wife beating. On the contrary, mothers who did not have legal assets ownership as much as 1.35 times could prevent their children from not being fed with minimum meal frequency compared to mothers who had legal assets.

\section{Discussion}

Our model showed that the Indonesia IYCF practice was varied by child's characteristics and by each dimension of women's empowerment. The study's findings indicated that several dimensions of women's empowerment simultaneously contributed to the improvement of IYCF practice. Mother without acceptance of domestic violence was a preventive factor of inadequate feeding practice. It is assumed that mothers who reported wife beating was not justified in any circumstances might lead to enhanced psychological wellbeing. Mother's mental state was one of significant predictors of parenting behaviour, as stated in Belsky's parenting model. Mother's negative affect, 
such as depression and anxiety, contributed to inadequate feeding practice (Madlala \& Kassier, 2018; Rodgers et al., 2014). On one hand, attitudinal acceptance of domestic violence significantly predicted mother's experience of intimate partner violence (IPV) (Amir-ud-Din, Fatima, \& Aziz, 2018), whereas IPV was associated with mother's depression, inadequate feeding practice and child's stunting (Neamah et al., 2018; Sobkoviak, Yount, \& Halim, 2012; Zureick-Brown et al., 2015).

Final model showed that children from mothers without legal asset ownerships was significantly associated with meeting minimum dietary diversity, minimum meal frequency and minimum acceptable diets. Yet, control over women's cash earning had significantly influenced the indicators of minimum dietary diversity and minimum acceptable diet. It is assumed that control over personal earning was a form of self-efficacy. Mothers with self-efficacy were positively associated with adequate feeding practice (Barrett, Thompson, \& Bentley, 2016), as implied by Belsky's parenting model. Legal asset ownerships did not have an independent effect on adequate feeding practice. Instead, legal asset ownerships must be modified with independent and effective use of the ownerships (Narciso \& Henriques, 2019). In this case, control over personal assets implied the independent use of ownerships (Johnson, Kovarik, Meinzen-Dick, Njuki, \& Quisumbing, 2016; Malapit \& Quisumbing, 2015). Previous studies indicated that women's empowerment in agriculture (including control and legal ownership of land and cattle) was positively associated with children's minimum dietary diversity and minimum acceptable diet (Komatsu, Malapit, \& Theis, 2018; Malapit \& Quisumbing, 2015; Sraboni, Malapit, Quisumbing, \& Ahmed, 2014).

Bivariate regression shows the influence of working mothers on children being fed in compliance with standard infant and young child feeding recommendations. Employed mothers would have better income and might perform IYCF practice significantly (G. N. Khan et al., 2017). However, in the final model adjusted for other factors, working mothers were not associated with children being fed with minimum dietary diversity and minimum acceptable diet. Heavy workload might reduce mother's time to get involved in IYCF practice (Ahishakiye et al., 2019; Roshita, Schubert, \& Whittaker, 2013; Wuneh, Ahmed, Bezabih, \& Reddy, 2019).

Our model shows no association between mother's participation in household decision making and IYCF practice. Most of Indonesian mothers were not involved in child feeding practice because they relied too much on other caregivers and child will power (Roshita et al., 2013; Vaezghasemi, Öhman, Ng, Hakimi, \& Eriksson, 2020). However, opposite reports identified that participation in household decision making had positive influence on adequate feeding practice and child's better nutritional status (Dhami, Ogbo, Osuagwu, \& Agho, 2019a; Ickes et al., 2018; J. R. Khan et al., 2019; Na et al., 2015; Shroff et al., 2011). Indonesian mother's participation in child-related decisions could increase her well-being, yet the burden of her responsibility would increase along with her participation in household expenditure decisions (Fernandez et al., 2015). DHS questionnaires exclude participation in child care. Thus, it is suggested to put child-related decisions as an indicator of women's empowerment within DHS measures.

Regarding overall empowerment, it is important to summarize that no single indicator is sufficient to explain adequate feeding practice. It is also assumed mother's psychological wellbeing as the impact of empowerment leads to appropriate IYCF practice in Indonesia.

Child age was the most important factor that influenced each indicator of IYCF practice that could be seen from the highest adjusted odds ratio in the final model. As child age increased, they were more likely to be fed with minimum dietary diversity, minimum meal frequency and minimum acceptable diet requirements. Similar reports were obtained from Nepal (Na, Aguayo, Arimond, Dahal, et al., 2018a), India (Nguyen et al., 2018) and Ethiopia (Wuneh et al., 2019). Previous studies reported the ability to digest soft, semi solid and solid foods improved as child age increased (Alder et al., 2004; Fein, Labiner-Wolfe, Scanlon, \& Grummer-Strawn, 2008). Another explanation might be attributable with communication and motor development in a child's first two years of life (Addo et al., 2020), thus allowing mothers to be able to develop responsive feeding practice significantly. This is in line with Piaget's sensorimotor theory regarding child's cognitive development throughout the first two years of age.

Results of our study showed that children from more prosperous households were more likely to meet official minimum dietary diversity, minimum meal frequency and minimum acceptable diet requirements rather than the destitute ones. In addition, children in urban areas also could meet each indicator of IYCF practice than their counterparts in rural areas. IYCF practice was associated with the household's financial resources (Ahishakiye et al., 2019; Helle, Hillesund, \& Overby, 2018; G. N. Khan et al., 2017; Maciel et al., 2018; Na, Aguayo, Arimond, Narayan, \& Stewart, 2018b) and urban-rural location (Nguyen et al., 2018; Tassew et al., 2019). It implies that wealth and living in urban areas determine the ease of accessing resources to meet child's adequate feeding 
practice.

Due to child sex, our study shows inconsistent findings. In bivariate analysis, male children were at higher risk of not being fed in compliance with minimum diet diversity. However, after adjusted with other factors in the final model, child sex was not associated with minimum diet diversity. On the other hand, male children were more likely to be fed with minimum meal frequency and minimum acceptable diet. There has been parental proportionate allocation of investment resources to sons and daughters in Indonesia (Kevane \& Levine, 2000). Furthermore, the diversity of gender preference and sex imbalance could not be justified since DHS measures are a nation-wide survey in 34 provinces of Indonesia (Guilmoto, 2015). Child sex bias could be due to individual characteristics, which needs further exercises.

Infants and young children of multiparous mothers, especially mothers with three or more children, were at risk of not being fed in compliance with WHO infant feeding recommendation. Those who were born from mothers with lower parity achieved significant feeding practice (Nguyen et al., 2018; Tadesse, 2018). This might be due to the fact that mothers with low parity will invest more in interactive time and provide their child better nutrition care. Mother parity is critical to promote the improvement of infant and young child feeding practice.

Maternal age is not significantly associated with IYCF practice. There are contradictory findings related to maternal age. Some studies reported that adolescent mothers provided more inadequate feeding practice to their child (Costa, Antunes, Cabral, \& Silva, 2018; Helle et al., 2018), while others identified that mothers with advanced age put their children at higher risk of not being fed in compliance with official infant and young child feeding recommendation (G. N. Khan et al., 2017; Tadesse, 2018).

Attitude towards domestic violence and heavy workload may impede mother's self-efficacy. On the other hand, the independent use of personal asset may improve a mother's self-efficacy. Mother's self-efficacy was important for adequate IYCF practice (Lamstein, 2017; Sarrassat et al., 2019). However, mother's self-efficacy was often thwarted by limitation in household resources and living in rural areas with limited access. Therefore, household resources and living in urban areas were also considered to play a pivotal role for a mother with self-efficacy to feed her child with appropriate feeding practice.

The strength of this study was the large nationally representative data that makes the findings generalise to national level. However, this study has some limitations. Data on IYFC is based on retrospective information provided by mothers, which may be subject to recall bias. The design study of cross-sectional could not determine causality between the variables, but only measure the association. Therefore, it was difficult to conclude a cause-effect relationship. Although this study uses a large and national representative data set, in depth analysis was needed to examine the process mechanism of our findings. Likewise, there was a call for further discussion on the questions about child-related decisions as an indicator of women's empowerment within DHS nationwide survey.

\section{Conclusion}

Overall, this study revealed that women's empowerment is important for children being fed in compliance with WHO feeding practice recommendations. IYCF practice was associated with mother without legal asset ownership, yet this mother without acceptance attitudinal of intimate partner violence in any circumstances and supported by the ability to control over personal income and being employed without heavy workload. In accordance with individual characteristics, young children with advanced age, who live in urban areas, and from higher wealth status were more likely to meet each indicator of IYCF practice. A maximum of two parity, as a maternal individual characteristic, was very critical to improve the opportunity for children to be fed in compliance with official feeding practice recommendation.

\section{Authors' Contribution}

MDP conceptualized and designed the study.

MG ensured the method and statistical analysis.

All authors are the main contributors; and equally reviewed and provided input on the final article.

\section{Competing Interests Statement}

The authors declare that they have no conflicts of interest.

\section{References}

Addo, O. Y., Tripp, K., Nanama, S., Albert, B., Sandalinas, F., Nanema, A., ... Locks, L. M. (2020). An Integrated Infant and Young Child Feeding and Small-Quantity Lipid-based Nutrient Supplementation Program Is Associated with Improved Gross Motor and Communication Scores of Children 6-18 Months in the 
Democratic Republic of Congo. Journal of Pediatrics. https://doi.org/10.1016/j.jpeds.2020.01.023

Ahishakiye, J., Bouwman, L., Brouwer, I. D., Matsiko, E., Armar-Klemesu, M., \& Koelen, M. (2019). Challenges and responses to infant and young child feeding in rural Rwanda: A qualitative study. Journal of Health, Population and Nutrition, 38(1), 1-10. https://doi.org/10.1186/s41043-019-0207-z

Ahmad, A., Madanijah, S., Dwiriani, C. M., \& Kolopaking, R. (2018). Complementary feeding practices and nutritional status of children 6-23 months old: Formative study in Aceh, Indonesia. Nutrition Research and Practice, 12(6), 512-520. https://doi.org/10.4162/nrp.2018.12.6.512

Alder, E. M., Williams, F. L. R., Anderson, A. S., Forsyth, S., Florey, C. du V., \& van der Velde, P. (2004). What influences the timing of the introduction of solid food to infants? British Journal of Nutrition, 92(3), 527-531. https://doi.org/10.1079/bjn20041212

Amir-ud-Din, R., Fatima, S., \& Aziz, S. (2018). Is Attitudinal Acceptance of Violence a Risk Factor? An Analysis of Domestic Violence Against Women in Pakistan. Journal of Interpersonal Violence, (2), 1-28. https://doi.org/10.1177/0886260518787809

Barrett, K. J., Thompson, A. L., \& Bentley, M. E. (2016). The influence of maternal psychosocial characteristics on infant feeding styles. Appetite, 103, 396-402. https://doi.org/10.1016/j.appet.2016.04.042

Belsky, J. (1984). The Determinants of Parenting: A Process Model. Child Development, 55(1), 83-96. https://doi.org/10.2307/1129836

Bulte, E., \& Lensink, R. (2019). Women's empowerment and domestic abuse: Experimental evidence from Vietnam. European Economic Review, 115, 172-191. https://doi.org/10.1016/j.euroecorev.2019.03.003

Cornish, H., Walls, H., Ndirangu, R., Ogbureke, N., Bah, O. M., Tom-Kargbo, J. F., ... Ranganathan, M. (2019). Women's economic empowerment and health related decision-making in rural Sierra Leone. Culture, Health and Sexuality, O(0), 1-18. https://doi.org/10.1080/13691058.2019.1683229

Costa, K. A. O. da, Antunes, M. M. de C., Cabral, P. C., \& Silva, G. A. P. da. (2018). Feeding style of adolescent mothers and complementary feeding practice of their infants TT - Estilo alimentar adotado por mães adolescentes e práticas da alimentação complementar dos seus filhos lactentes. Revista de Nutrição, 31(1), 49-58. https://doi.org/10.1590/1678-98652018000100005

Dhami, M. V., Ogbo, F. A., Osuagwu, U. L., \& Agho, K. E. (2019a). Prevalence and factors associated with complementary feeding practices among children aged 6-23 months in India: a regional analysis. BMC Public Health, 19(1), 1034. https://doi.org/10.1186/s12889-019-7360-6

Dhami, M. V., Ogbo, F. A., Osuagwu, U. L., Ugboma, Z., \& Agho, K. E. (2019b). Stunting and severe stunting among infants in India: the role of delayed introduction of complementary foods and community and household factors. Global Health Action, 12(1). https://doi.org/10.1080/16549716.2019.1638020

Fein, S. B., Labiner-Wolfe, J., Scanlon, K. S., \& Grummer-Strawn, L. M. (2008). Selected complementary feeding practices and their association With maternal education. Pediatrics, 122(SUPPL. 2). https://doi.org/10.1542/peds.2008-13151

Fernandez, A., Della Giusta, M., \& Kambhampati, U. S. (2015). The Intrinsic Value of Agency: The Case of Indonesia. World Development, 70, 92-107. https://doi.org/10.1016/j.worlddev.2014.12.020

Gram, L., Morrison, J., \& Skordis-Worrall, J. (2019). Organising Concepts of 'Women's Empowerment' for Measurement: A Typology. Social Indicators Research, 143(3), 1349-1376. https://doi.org/10.1007/s11205-018-2012-2

Guilmoto, C. Z. (2015). Mapping the diversity of gender preferences and sex imbalances in Indonesia in 2010. Population Studies, 69(3), 299-315. https://doi.org/10.1080/00324728.2015.1091603

Harding, K. L., Aguayo, V. M., \& Webb, P. (2018). Birthweight and feeding practices are associated with child growth outcomes in South Asia. Maternal and Child Nutrition, 14(May 2018), 1-12. https://doi.org/10.1111/men.12650

Helle, C., Hillesund, E. R., \& Overby, N. C. (2018). Timing of complementary feeding and associations with maternal and infant characteristics: A Norwegian cross-sectional study. PLoS ONE, 13(6), 1-20. https://doi.org/10.1371/journal.pone.0199455

Ickes, S. B., Wu, M., Mandel, M. P., \& Roberts, A. C. (2018). Associations between social support, psychological well-being, decision making, empowerment, infant and young child feeding, and nutritional status in 
Ugandan children ages 0 to 24 months. Maternal and Child Nutrition, 14(1), 1-11. https://doi.org/10.1111/mcn.12483

IFC. (2018). Demographic and Health Surveys: Standard Recode Manual for DHS 7. In The Demographic and Health Survey Program. Retrieved from http://www.measuredhs.com/pubs/pdf/DHSG1/Guide_to_DHS_Statistics_29Oct2012_DHSG1.pdf\%5Cnhtt $\mathrm{p}: / /$ citeseerx.ist.psu.edu/viewdoc/download?doi $=10.1 .1 .431 .8235 \& \mathrm{rep}=\mathrm{rep} 1 \&$ type $=\mathrm{pdf}$

Johnson, N. L., Kovarik, C., Meinzen-Dick, R., Njuki, J., \& Quisumbing, A. (2016). Gender, Assets, and Agricultural Development: Lessons from Eight Projects. World Development, 83, 295-311. https://doi.org/10.1016/j.worlddev.2016.01.009

Kabeer, N. (1999). Resources, agency, achievements: Reflections on the measurement of women's empowerment. Development and Change, 30(3), 435-464. https://doi.org/10.1111/1467-7660.00125

Kevane, M., \& Levine, D. (2000). The Changing Status of Daughters in Indonesia (No. 77-00). Retrieved from https://www.irle.berkeley.edu/files/2000/The-Changing-Status-of-Daughters-in-Indonesia.pdf

Khan, G. N., Ariff, S., Khan, U., Habib, A., Umer, M., Suhag, Z., ... Soofi, S. (2017). Determinants of infant and young child feeding practices by mothers in two rural districts of Sindh, Pakistan: A cross-sectional survey. International Breastfeeding Journal, 12(1), 1-8. https://doi.org/10.1186/s13006-017-0131-z

Khan, J. R., Awan, N., \& Sheikh, M. T. (2019). A Multilevel and Spatial Analysis of the Infant and Young Child Feeding Practices and Associated Factors among the Under-2 Aged Children in Bangladesh. Child Care in Practice, O(0), 1-18. https://doi.org/10.1080/13575279.2019.1680528

Komatsu, H., Malapit, H. J. L., \& Theis, S. (2018). Does women's time in domestic work and agriculture affect women's and children's dietary diversity? Evidence from Bangladesh, Nepal, Cambodia, Ghana, and Mozambique. Food Policy, 79(July), 256-270. https://doi.org/10.1016/j.foodpol.2018.07.002

Lamstein, S. A. (2017). Women's empowerment in Nigeria: baseline data from an evaluation of the Community Infant and Young Child Feeding (C-IYCF) Counselling Package. The Lancet Global Health, 5, S29. https://doi.org/10.1016/s2214-109x(17)30136-5

Maciel, B. L. L., Moraes, M. L., Soares, A. M., Cruz, I. F. S., De Andrade, M. I. R., Filho, J. Q., ... Lima, A. A. M. (2018). Infant feeding practices and determinant variables for early complementary feeding in the first 8 months of life: Results from the Brazilian MAL-ED cohort site. Public Health Nutrition, 21(13), 2462-2470. https://doi.org/10.1017/S136898001800099X

Madlala, S. S., \& Kassier, S. M. (2018). Antenatal and postpartum depression: Effects on infant and young child health and feeding practices. South African Journal of Clinical Nutrition, 31(1), 1-7. https://doi.org/10.1080/16070658.2017.1333753

Malapit, H. J. L., \& Quisumbing, A. R. (2015). What dimensions of women's empowerment in agriculture matter for nutrition in Ghana? Food Policy, 52, 54-63. https://doi.org/10.1016/j.foodpol.2015.02.003

Mishra, K., \& Sam, A. G. (2016). Does Women's Land Ownership Promote Their Empowerment? Empirical Evidence from Nepal. World Development, 78, 360-371. https://doi.org/10.1016/j.worlddev.2015.10.003

Murshid, N. S. (2018). Microfinance Participation and Women's Decision-Making Power in the Household in Bangladesh. Journal of Social Service Research, 44(3), 308-318. https://doi.org/10.1080/01488376.2018.1472170

Na, M., Aguayo, V. M., Arimond, M., Dahal, P., Lamichhane, B., Pokharel, R., ... Stewart, C. P. (2018a). Trends and predictors of appropriate complementary feeding practices in Nepal: An analysis of national household survey data collected between 2001 and 2014. Maternal and Child Nutrition, 14(October 2017), 1-13. https://doi.org/10.1111/mcn.12564

Na, M., Aguayo, V. M., Arimond, M., Narayan, A., \& Stewart, C. P. (2018b). Stagnating trends in complementary feeding practices in Bangladesh: An analysis of national surveys from 2004-2014. Maternal and Child Nutrition, 14(April). https://doi.org/10.1111/mcn.12624

Na, M., Jennings, L., Talegawkar, S. A., \& Ahmed, S. (2015). Association between women's empowerment and infant and child feeding practices in sub-Saharan Africa: An analysis of Demographic and Health Surveys. Public Health Nutrition, 18(17), 3155-3165. https://doi.org/10.1017/S1368980015002621

Narciso, V. J. S., \& Henriques, P. D. S. (2019). Does the matrilineality make a difference? Land, kinship and 
women's empowerment in Bobonaro district, Timor-Leste. Journal of the Asia Pacific Economy, 0(0), 1-23. https://doi.org/10.1080/13547860.2019.1665295

Neamah, H. H., Sudfeld, C., McCoy, D. C., Fink, G., Fawzi, W. W., Masanja, H., ... Fawzi, M. C. S. (2018). Intimate partner violence, depression, and child growth and development. Pediatrics, 142(1). https://doi.org/10.1542/peds.2017-3457

Nguyen, P. H., Avula, R., Headey, D., Tran, L. M., Ruel, M. T., \& Menon, P. (2018). Progress and inequalities in infant and young child feeding practices in India between 2006 and 2016. Maternal and Child Nutrition, 14(May), 1-11. https://doi.org/10.1111/mcn.12663

Rodgers, R. F., Paxton, S. J., McLean, S. A., Campbell, K. J., Wertheim, E. H., Skouteris, H., \& Gibbons, K. (2014). Maternal negative affect is associated with emotional feeding practices and emotional eating in young children. Appetite, 80, 242-247. https://doi.org/10.1016/j.appet.2014.05.022

Roshita, A., Schubert, E., \& Whittaker, M. (2013). Child Feeding Practices in Families of Working and Nonworking Mothers of Indonesian Middle Class Urban Families: What Are the Problems? Ecology of Food and Nutrition, 52(4), 344-370. https://doi.org/10.1080/03670244.2012.707438

Samarakoon, S., \& Parinduri, R. A. (2015). Does Education Empower Women? Evidence from Indonesia. World Development, 66, 428-442. https://doi.org/10.1016/j.worlddev.2014.09.002

Sarrassat, S., Ganaba, R., Some, H., Cresswell, J. A., Diallo, A. H., Cousens, S., \& Filippi, V. (2019). Suboptimal infant and young child feeding practices in rural Boucle du Mouhoun, Burkina Faso: Findings from a cross-sectional population-based survey. PLoS ONE, 14(11), 1-18. https://doi.org/10.1371/journal.pone.0224769

Shroff, M. R., Griffiths, P. L., Suchindran, C., Nagalla, B., Vazir, S., \& Bentley, M. E. (2011). Does maternal autonomy influence feeding practices and infant growth in rural India? Soc Sci Med, 73(3), 447-455. https://doi.org/10.1016/j.socscimed.2011.05.040.Does

Si Han, Y., \& Pei Jun, W. (2013). Parental Involvement in Child's Development: Father vs. Mother. Open Journal of Medical Psychology, 02(04), 1-6. https://doi.org/10.4236/ojmp.2013.24b001

Sobkoviak, R. M., Yount, K. M., \& Halim, N. (2012). Domestic violence and child nutrition in Liberia. Social Science and Medicine, 74(2), 103-111. https://doi.org/10.1016/j.socscimed.2011.10.024

Sraboni, E., Malapit, H. J., Quisumbing, A. R., \& Ahmed, A. U. (2014). Women's empowerment in agriculture: What role for food security in Bangladesh? World Development, 61, 11-52. https://doi.org/10.1016/j.worlddev.2014.03.025

Statistics Indonesia (BPS). (2019, February). Booklet Sakernas Februari 2019. Retrieved from https://www.bps.go.id/publication/download.html?nrbvfeve=NTQyOGUxMTE3ZTEzOGM2ZDM2NzY5 MzYz\&xzmn=aHR0cHM6Ly93d3cuYnBzLmdvLmlkL3B1YmxpY2F0aW9uLzIwMTkvMTEvMjcvNTQy OGUxMTE3ZTEzOGM2ZDM2NzY5MzYzL2Jvb2tsZXQtc3VydmVpLWFuZ2thdGFuLWtlcmphLW5hc21 vbmFsLWZIYnJ1YXJpLTIwMTkuaHRtbA\%3D\%3D\&twoadfnoarfeauf=MjAyMC0wNy0wMSAxNjoxNT owMA\%3D\%3D

Statistics Indonesia (BPS). (n.d). Indeks Pemberdayaan Gender (IDG) Menurut Provinsi, 2010-2018. Retrieved July 1 , 2020, from https://www.bps.go.id/dynamictable/2018/08/15/1573/-idg-indeks-pemberdayaan-gender-idg-menurut-provi nsi-2010-2017.html

Tadesse, A. (2018). Predictors of infant and young feeding practices among children 6-23 months old in Bennatsemayworeda, Ethiopia. Journal of Nutritional Health \& Food Engineering, 8(6). https://doi.org/10.15406/jnhfe.2018.08.00304

Tassew, A. A., Tekle, D. Y., Belachew, A. B., \& Adhena, B. M. (2019). Factors affecting feeding 6-23 months age children according to minimum acceptable diet in Ethiopia: A multilevel analysis of the Ethiopian Demographic Health Survey. PLoS ONE, 14(2), 1-14. https://doi.org/10.1371/journal.pone.0203098

Vaezghasemi, M., Öhman, A., Ng, N., Hakimi, M., \& Eriksson, M. (2020). Concerned and Conscious, but DefenselessThe intersection of gender and generation in child malnutrition in Indonesia: a qualitative grounded theory study. Global Health Action, 13(1), 1744214. https://doi.org/10.1080/16549716.2020.1744214

Weise, A. S. (2014). WHA Global Nutrition Targets 2025: Stunting Policy Brief. In World Health Organization. 
https://doi.org/WHO/NMH/NHD/14.3

WHO. (2006). Mental health and psychosocial well-being among children in severe food shortage situations. In World Health Organization (Vol. 13). https://doi.org/WHO/MSD/MER/06.1

Wuneh, A. G., Ahmed, W., Bezabih, A. M., \& Reddy, P. S. (2019). Dietary Diversity and Meal Frequency Practices among Children Aged 6-23 Months in Agro Pastoral Communities in Afar Region, Ethiopia: A Cross-sectional Study. Ecology of Food and Nutrition, 58(6), 575-596. https://doi.org/10.1080/03670244.2019.1644328

Zureick-Brown, S., Lavilla, K., Yount, K. M., Neamah, H. H., Sudfeld, C., McCoy, D. C., ... Fawzi, M. C. S. (2015). Intimate partner violence and infant feeding practices in India: A cross-sectional study. Maternal and Child Nutrition, 142(4), 792-802. https://doi.org/10.1111/mcn.12057

\section{Copyrights}

Copyright for this article is retained by the author(s), with first publication rights granted to the journal.

This is an open-access article distributed under the terms and conditions of the Creative Commons Attribution license (http://creativecommons.org/licenses/by/4.0/). 